\title{
Personal Branding Influencer di Media Sosial TikTok
}

\author{
Yemikaori Yumna Ulya Ishihara, Roswita Oktavianti \\ yemkao23@gmail.com, roswitao@,fikom.untar.ac.id \\ Fakultas Ilmu Komunikasi Universitas Tarumanagara
}

\begin{abstract}
Personal branding is widely used as a communication strategy to instill a positive perception of a person to the public. Personal branding is also done directly and indirectly through social media. An influencer needs to have a strong personal branding to differentiate him from other influencers. One of the Tik Tok influencers is Dhea Dillah with the Tik Tok account@dillaprb. This study aims to determine how Dhea Dillah's personal branding is on Tik Tok social media. The method used is descriptive qualitative with 11 indicators of personal branding criteria according to Rampersad, namely authenticity, integrity, consistency, specialization, authority, diversity, relevance, visibility, persistence, kindness, and performance. This research shows that influencers have characters that are in line with their personal ambitions, namely creating Tik Tok content to inform their followers. Next, influencers are also consistent with a focus on one area, experience, and professionalism towards clients, including making self-improvement if they receive criticism or evaluation.
\end{abstract}

Keywords: Influencer, Personal Branding, Social Media, TikTok

\begin{abstract}
Abstrak
Personal branding banyak dilakukan sebagai salah satu strategi komunikasi untuk menanamkan persepsi positif seseorang kepada publik. Personal branding juga dilakukan secara langsung dan tidak langsung melalui media sosial. Seorang influencer perlu memiliki personal branding yang kuat untuk membedakannya dengan influencer lain. Salah satu influencer Tik Tok yaitu Dhea Dillah dengan akun Tik Tok @dillaprb. Penelitian ini bertujuan untuk mengetahui bagaimana personal branding yang dilakukan Dhea Dillah dalam media sosial Tik Tok. Metode yang digunakan yaitu deskriptif kualitatif dengan indikator 11 kriteria personal branding menurut Rampersad yaitu keontentikan, integritas, konsisten, spesialisasi, wibawa, keberbedaan, relevan, visibilitas, kegigihan, kebaikan, dan kinerja. Penelitian ini menunjukkan bahwa influencer memiliki karakter yang sesuai dengan ambisi pribadi yaitu membuat konten Tik Tok untuk memberi informasi kepada pengikutnya. Berikutnya, influencer juga konsisten dengan fokus pada satu bidang, berpengalaman, dan profesional terhadap klien termasuk membuat perbaikan diri jika mendapat kritik atau evaluasi.
\end{abstract}

Kata kunci: Influencer, Media Sosial, Personal Branding, TikTok

\section{Pendahuluan}

Kehadiran media sosial Tik Tok dapat membangun sebuah brand. Tik Tok juga dapat membangun personal branding pemiliknya (Soraya, 2017). Peter dan Rampersad mengungkapkan kriteria-kriteria membangun personal branding yang efektif, meliputi : 1) Keotentikan (Authenticity). Mencerminkan diri sendiri sesuai dengan visi, nilai-nilai, karakter yang dimiliki sendiri yang diselaraskan dengan ambisi pribadi; (2) Integritas (Integrity). Melaksanakan kode moral perilaku yang ditetapkan oleh ambisi pribadi; (3) Konsisten (Consistency); (4) Spesialisasi 
(Specialization). Fokus pada satu bidang terspesialisasi yang unik; (5) Wibawa (Authority); (6) Keberbedaan (Differentiation); (7) Relevan (Relevan); (8) Visibilitas (Visibility). Personal Branding yang dilakukan harus diulang secara terus menerus sehingga dapat tertanam di benak khalayak; (9) Kegigihan (Persistence). Satu merek yang dibangun memerlukan waktu untuk tumbuh. Harus bersabar, konsisten, jangan menyerah dan percaya terhadap diri sendiri; (10) Kebaikan (Goodwill). Merek pribadi akan menghasilkan hasil yang bertahan lama dan baik jika itu positif. Merek pribadi yang dibuat harus berkaitan dengan hal yang positif dan bermanfaat. Orangorang berbisnis dengan apa yang mereka sukai; (11) Kinerja (Performance) (Rachmawati \& Ali, 2018).

Influencer yaitu seseorang yang dapat mempengaruhi orang lain. Seorang influencer bukan selalu selebrity, tetapi semua orang bisa dikatakan sebagai influencer jika orang tersebut memiliki keunikan, kemampuan atau konten yang bisa menginspirasi pengikutnya (followers), adapun alasan influencer digunakan oleh perusahaan adalah untuk meningkatkan kesadaran (awareness) mengedukasi target konsumen, meningkatkan followers dan tentunya untuk meningkatkan penjualan (Sugiharto \& Ramadhana, 2018). Salah satunya adalah Dhea Dillah yang merupakan influencer Tik Tok.

Dhea Dillah dengan akun Tik Tok@dillaprb merupakan salah satu pengguna Tik Tok yang mempunyai 441,6 ribu pengikut atau followers. Nama Dhea Dillah booming saat pertama kali mengunggah konten video sedang membuat sebuah busana yang terinspirasi dari film "Clueless". Penontonnya mencapai 974,1 ribu dan sebanyak 130,9 ribu menyukai konten tersebut. Penulis tertarik untuk mengetahui bagaimana cara influencer membangun personal branding melalui konten di media sosial Tik Tok? Tujuan penelitian ini adalah untuk mengetahui cara influencer membangun personal branding melalui konten di media sosial Tik Tok.

\section{Metode Penelitian}

Peneltian ini membahas bentuk personal branding Dhea Dillah dalam akun Tik Tok@dillaprb. Penelitian ini dilaksanakan pada bulan Oktober 2020. Jenis penelitian yang digunakan dalam penelitian ini adalah metode kualitatif dengan jenis pendekatan deskriptif kualitatif. Penelitian ini menggunakan metode penelitian kualitatif yang bersifat deskriptif atau penelitian deskriptif kualitatif.

Subjek penelitian yaitu Dhea Dillah selaku influencer Tik Tok dan objek penelitiannya adalah personal branding yang dilakukan oleh influencer Dhea Dillah pada akun Tik Toknya. Teknik pengumpulan yang digunakan dalam penelitian ini menggunakan data primer dan sekunder. Peneliti melakukan wawancara dengan Dhea Dillah sebagai informan. Wawancara dilakukan dengan menggunakan voice call whatsapp dan voice notes LINE dikarenakan situasi pandemi Covid-19 yang tidak memungkinkan untuk bertemu. Data sekunder yang digunakan yaitu mengumpulkan dokumentasi. Dokumen dalam penelitian ini berupa data dalam bentuk file foto, artikel melalui instagram dan data yang berkaitan dengan bentuk personal branding.

Pada penelitian ini, peneliti menggunakan triangulasi teknik dengan cara membandingkan wawancara dengan narasumber satu yaitu sebagai influencer dan narasumber 2 dan 3 sebagai followers-nya. Narasumber follower akun Tik Tok influencer yaitu Laura Berlian dan Rizky Berliana. 


\section{Hasil Penelitian}

Cara influencer membangun personal branding melalui konten di media sosial Tik Tok yaitu:

\section{Keotentikan}

Keotentikan dalam Rampersad (2008:19) adalah merek yang dibangun harus dari kepribadian sejati dan harus mencerminkan karakter, perilaku, nilai, serta visi pelaku personal branding tersebut. Dengan cara itu, pelaku personal branding memiliki kesamaan pribadi dalam dunia nyata dengan apa yang di aplikasikan untuk membangun personal branding yang otentik. Personal branding yang dilakukan influencer Dilla dalam akun @dillaprb dalam hal visi, nilai, karakter,serta perilaku adalah Dilla mempunyai karakter yang berbeda dari orang lain yaitu dengan hobinya yang suka mengecat rambutnya sendiri dan menjadikannya sebagai ciri khas. Hal ini dikatakan oleh Dilla:

"Cuma ya gitu deh jadi kayak, misal kalo menurut gue self-branding gue itu misal I like color hair dari dulu dari dulu gue SMP, SMA, kuliah dari yemi ketemu gue rambut udah begini. That's how I make my self different from other people sekalipun orang lain juga banyak ya rambutnya warna-warni. Ya udah I add other things misal kayak I like wearing boots all the time. It will make them kayak karena emang if you wanna get recognize by people you gotta do something that make me stand out" (Dhea Dillah)

\section{Integritas}

Agar content creator dipandang positif di mata masyarakat maka seorang influencer harus mematuhi moral yang berlaku di masyarakat serta memiliki perilaku positif selaras dengan ambisi pribadi. Selain keontentikan, dalam melakukan personal branding juga harus memperhatikan kriteria lainnya yaitu integritas. Rampersad (2008:19) menyatakan integritas adalah kode moral yang merupakan penerapan perilaku kepada khalayaknya. Penerapan tersebut juga untuk bisa dipandang positif oleh khalayaknya. Dilla sebagai influencer menerapkan perilaku positif kepada khalayaknya dengan cara berinteraksi dengan followers sepertihalnya sahabat.

\section{Konsistensi}

Kriteria lainnya adalah konsisten. Menurut Montoya dan Rampersad (2008:19) adalah seseorang memerlukan konsistensi dalam berperilaku, seperti halnya yang dilakukan oleh influencer Dilla dalam membuat konten-konten di Tik Tok. Dilla selalu mengunggah konten yang bertemakan fashion dan terus menerus membuat konten sesuai minatnya yaitu fashion.

\section{Spesialisasi}

Untuk membangun personal branding yang otentik diperlukan adanya spesialisasi atau bakat yang ditonjolkan oleh pelaku personal branding. Menurut Rampersad (2008:19) spesialisasi merupakan satu bidang bakat atau keterampilan.

Menurut hasil wawancara, terdapat spesialisasi yang influencer Dilla sengaja tonjolkan dan diperlihatkan kepada followers-nya yaitu mengenai tutorial menjahit dan beberapa mengenai fashion. Dengan adanya spesialisasi, influencer Dilla dikenal oleh khalayak sebagai seorang content creator Tik Tok dalam bidang fashion. 
Yemikaori Yumna Ulya Ishihara, Roswita Oktavianti: Personal Branding Influencer di Media Sosial TikTok

\section{Wibawa}

Wibawa atau disebut otoritas menurut Rampersad (2008:19) yaitu dapat diakui dalam bidang tertentu dimana pelaku memang sudah berpengalaman di bidangnya dalam melakukan personal branding. Influencer Dilla yang sudah berpengalaman dalam cat rambut dipercaya oleh sebuah brand cat rambut. Penelitian ini memperkuat penelitian yang dilakukan oleh Sugiharto dan Ramadhana (2018), yang menunjukkan dalam penelitiannya bahwa brand Maybelline mempercayakan influencer Tasya Farasya dalam acaranya. Pada penelitian ini, influencer Dilla dikontrak selama setahun untuk melakukan beberapa hal untuk membuat konten mengenai perawatan rambut ataupun pengecatan rambut. Hal ini dikatakan oleh Dilla:

"Ceritanya waktu itu gabut, rambut gue warnanya udah abu-abu luntur terus gue lagi kelas, lagi gabut kelas gue, selisih 4 jam, terus 'Dilla ngecat rambut kali ya' terus bilang ke nyokap gue 'adek tiktokin kali ya'. Kata nyokap gue, 'yaudah bikin aja' itu kayaknya di Tiktok lagi rame tuh orang ngecat rambut pake Miranda. Gue dalam hati, oh yaudah. cuma emang kadang gue ngecat selalu pake itu waktu dulu ya. Terus yaudah gue Tiktokin aja, sebenernya intro-nya cuma kayak gue biasa cuma pake cat Shisedo, terus adanya Miranda, gara-gara semua orang pake itu yaudah gue cobain. Gue bingung mikir title-nya clickbait terus yang nonton 10 ribu, terus 5 menit, terus tiba-tiba 'oh rame ya' yaudah akhirnya Miranda nge reach-out ke gue mau ngirimin hair care, yaudah gue Tiktokin lah hair carenya." (Dhea Dillah)

\section{Keberbedaan}

Keberbedaan menurut Montoya dan Rampersad (2008:19) adalah membedakan diri berdasarkan brand. Merek pribadi perlu di ekspresikan secara unik dan beda dari pesaing lainnya. Perbedaan itu harus didefinisikan dengan jelas agar dapat ditangkap pesan merek pribadi anda. Influencer Dilla membuat konten mix and match dalam style dengan membalikkan baju dan celana yang harusnya dipakai di luar, lalu memakainya di dalam. Hal itu membuat para followers tertarik untuk mencoba hal yang baru dan semakin membuat followers kreatif dalam berpakaian. Hal ini dikatakan oleh Dilla:

"Ada hal simple yang bisa dilakuin orang, ada juga beberapa yang gue ngide-ngide aja kayak misalkan kayak baju yang dibalik, atau gak. Kayak pake bajunya monokrom atau gak, tabrakin aja warnanya, tapi warna ini sama warna ini. yaudah disitu gue mulai ngeliat view-nya lebih banyak ya." (Dhea Dillah)

Salah satu followers Dilla juga mengatakan bahwa ia baru menemukan content creator dalam bidang fashion yang membuat sewing tutorials. Hal ini juga dikatakan oleh Lili, salah satu follower:

"Terus juga aku liat-liat content creator yang kontennya tentang jait-menjait itu baru kak Dilla jadi ya itu aku jadi makin tertarik ngefollow kak Dilla."(Rizky Berliana). Hal itu yang menjadikan influencer Dilla berbeda dari yang lain.

\section{Relevan}

Dalam buku Rampersad (2008:19) relevan merupakan pesan sesuatu yang dianggap penting oleh audiens. Melalui akun Tik Tok@dillaprb, dengan spesialisasi yang dimiliki oleh dirinya membuat para audiens baru yang berdatangan sehingga followers Dilla semakin banyak jumlahnya dan itu semua termasuk followers yang sudah menganggap bahwa kesuksesan dalam berkonten sehingga membuat audiens merasa tertarik. Followers yang didapatkan juga merupakan target yang cocok dalam 
konten yang dibuat oleh Dilla sehingga keduanya sama-sama memiliki keuntungan. Dua followers Dilla, remaja perempuan berusia 18 tahun dan 21 tahun, menyatakan bahwa konten yang dibuat oleh influencer Dilla merupakan apa yang memang ingin mereka lihat. Dalam algoritma followers instagram Dilla juga membuktikan persentase yaitu $85 \%$ perempuan dan 15\% laki-laki. Rata-rata followers yaitu siswa SMA hingga mahasiswa.

\section{Visibilitas}

Dalam buku Rampersad (2008:19) membangun personal branding dibutuhkan visibilitas. Visibilitas merupakan pesan yang harus disiarkan berulangulang, terus-menerus, konsisten sampai tertanam di benak audiens. Dilla tidak terus menerus melakukan unggahan dalam membuat video menjahit di Tik Tok, tetapi ia selalu mengunggah video yang ingin ia unggah. Dengan begitu, followers Dilla tetap seimbang.

\section{Kegigihan}

Kegigihan merupakan konsistensi untuk membentuk personal branding, tidak mengubah haluan, setia, tidak menyerah, yakin terhadap diri sendiri dan tetap berfokus pada satu bidang (Rampersad, 2008:20). Saat pertama kali masuk media sosial Tik Tok, Dilla awalnya memikirkan jumlah followers karena ingin mengetahui apakah konten yang dibuatnya mempunyai kemajuan atau tidak. Namun informan tetap harus berpikir positif dan selalu membuat konten yang lebih interaktif. Candraningrum (2018) dalam penelitiannya menyebutkan bahwa semakin banyak followers, timbul masalah bagaimana cara mengelola media sosial supaya efektif untuk meningkatkan personal branding organisasinya.

\section{Kebaikan}

Kebaikan yang dimaksud dalam buku Rampersad adalah orang yang mau berbisnis dengan orang yang mereka sukai. Merek pribadi seseorang akan memberi hasil lebih baik dan tahan lebih lama bila dipandang secara positif oleh orang lain. Dilla mendapatkan respon positif dari khalayak yang dirinya miliki, melalui komentar-komentar di video Tik Toknya maupun di Instagram. Dilla memiliki hubungan yang baik juga kepada followers-nya, bahkan menganggap followers-nya adalah teman. Dila juga menjalin hubungan dengan para endorser atau brand yang telah mengajak kerja sama, sehingga banyak endorser atau brand yang menggunakan jasa Dilla lebih dari satu kali.

\section{Kinerja}

Menurut Rampersad (2008:29) kinerja merupakan elemen paling penting setelah brand seseorang dikenal. Bila seseorang tidak berbuat atau memperbaiki diri secara terus menerus, personal branding hanya menjadi sesuatu yang memalukan. Dalam kriteria terakhir ini, Dilla adalah seorang content creator di bidang fashion yang membangun personal branding melalui unggahan video pada aplikasi Tik Tok. Kegigihan dan kinerja, Dilla mempunyai rencana untuk tetap bisa menjadi apa yang diinginkan oleh followers-nya dan terus memperbaiki diri agar dapat mempertahankan personal brand yang telah ia bangun. Influencer Dilla juga menyertakan unsur kebaikan, agar tetap memiliki hubungan yang baik dan positif dengan khalayak. 
Followers juga memberikan harapan agar influencer Dilla tetap mengunggah konten sewing tutorials dan sering membuat konten yang berkualitas dan bermanfaat.

\section{Simpulan}

Personal branding merupakan hal yang sangat penting untuk semua orang, terutama untuk orang yang ingin membangun relasi kerja. Personal branding juga bisa disebut seni membuat merek seseorang, di mana kemampuan seseorang akan ditunjukkan sebagai sebuah brand.

Influencer Dilla sebagai content creator fashion melalui akun Tik Tok (a)dillaprb telah menerapkan sebelas dari kriteria personal branding. Pertama yakni keotentikan, sebagai influencer yang mempunyai karakter dan merupakan pelopor rambut warna warni karena suka mengecat rambutnya. Kedua, integritas di mana influencer akan terus melakukan hal positif. Ketiga, konsisten di mana influencer terus menerus membuat konten yaitu tentang fashion.

Keempat, spesialisasi yaitu dalam melakukan personal branding pada akun Tik Tok, konten akan kembali difokuskan pada sewing tutorials. Kelima adalah wibawa, influencer merupakan orang yang sudah berpengalaman dalam bidangnya sehingga banyak brand yang menghubungi dan mengunggah kembali hasil kerjasamanya dengan influencer. Keenam, keberbedaan yang dimiliki influencer yaitu keunikan sendiri dalam hal berpakaian dengan memakai baju yang terbalik, membuat dirinya menjadi beda dari orang lain. Ketujuh yaitu relevan di mana target audience sangat cocok dengan konten yang telah dibuat. Kedelapan visibilitas, di mana influencer akan mengunggah konten sesuai keinginan hati dan selalu membuat konten setiap minggunya.

Kesembilan yaitu kegigihan di mana influencer akan selalu membuat para audience senang dengan apa yang ia unggah. Kesepuluh, yaitu kebaikan di mana influencer berhasil berhubungan dengan banyak brand dan berhubungan baik dengan para followers. Terakhir kesebelas, yaitu kinerja di mana influencer memberikan konten yang menarik perhatian dan berkembang dengan baik.

\section{Ucapan Terima Kasih}

Terimakasih kepada seluruh pihak yang telah membantu penulis dalam menyelesaikan artikel ini. Terimakasih kepada kedua orang tua dan keluarga besar penulis, narasumber yang sudah membantu dan menyempatkan waktunya. Terima kasih pada sahabat penulis, Avilla Deva, Frity Saliaty, Adelia Amanda, Nia Puspita, Auliya Muqita, Rizka Dwi, dan Sherina Nuha yang selalu sabar dan tetap menyemangati penulis untuk menyelesaikan penelitian dan artikel jurnal ini.

\section{Daftar Pustaka}

Candraningrum, D. A. (2018). Teknologi Komunikasi Informasi Untuk Peningkatan Kesadaran Publik Pada Organisasi Sosial. Jurnal Komunikasi, 10(2), 177. https://doi.org/10.24912/jk.v10i2.2727

Rachmawati, Dita \& Ali, Dini Salmiyah Fithrah (2018). Analisis Kriteria Personal Branding Selebgram Non Selebriti (Studi Deskriptif Kualitatif Akun Instagram @Lippielust). Jurnal Komunikasi, 12(1), 34. 
https://doi.org/10.21107/ilkom.v12i1.3712

Rampersad. Hubert K. (2008). Authentic Personal Branding. Jakarta: PPM Publishing

Soraya, I. (2017). Personal Branding Laudya Cynthia Bella Melalui Instagram (Studi Deskriptif Kualitatif pada Akun Instagram @Bandungmakuta). Jurnal Komunikasi, $\quad 8(2), \quad 30-38$. http://ejournal.bsi.ac.id/ejurnal/index.php/jkom/article/view/2654.

Sugiharto, Shiya Azi \& Ramadhana, Maulana Rezi (2018). Pengaruh Kredibilitas Influencer terhadap Sikap pada Merek (Studi pada Mahasiswa Fakultas Komunikasi dan Bisnis Universitas Telkom). Jurnal Ilmu Politik Dan Komunikasi, VIII (2).

Susilowati. (2018). Pemanfaatan Aplikasi Tiktok Sebagai Personal Branding Di Instagram (Studi Deskriptif Kualitatif Pada Akun@bowo_allpennliebe). Jurnal Komunikasi, 9(2), 176-185. http://ejournal.bsi.ac.id/ejurnal/index.php/jkom 